\title{
BMJ open Spatial variation of salt intake in Britain and association with socioeconomic status
}

\author{
Chen Ji, Ngianga-Bakwin Kandala, Francesco P Cappuccio
}

To cite: Ji C, Kandala N-B, Cappuccio FP. Spatial variation of salt intake in Britain and association with socioeconomic status. BMJ Open 2013;3:e002246. doi:10.1136/bmjopen-2012002246

\section{- Prepublication history and} additional material for this paper are available online. To view these files please visit the journal online (http://dx.doi.org/10.1136/ bmjopen-2012-002246).

Received 22 October 2012 Revised 24 November 2012 Accepted 26 November 2012

This final article is available for use under the terms of the Creative Commons Attribution Non-Commercial 2.0 Licence; see http://bmjopen.bmj.com

Division of Mental Health \& Wellbeing, Warwick Medical School, University of Warwick, WHO Collaborating Centre for Nutrition, Coventry, UK

\footnotetext{
Correspondence to

Professor Francesco $P$ Cappuccio; f.p.cappuccio@ warwick.ac.uk
}

\author{
ABSTRACT \\ Objectives: To evaluate spatial effects of variation and \\ social determinants of salt intake in Britain. \\ Design: Cross-sectional survey. \\ Setting: Great Britain. \\ Participants: 2105 white male and female \\ participants, aged 19-64 years, from the British \\ National Diet and Nutrition Survey 2000-2001.
}

Primary outcomes: Participants' sodium intake measured both with a 7-day dietary record and a 24-h urine collection. By accounting for important linear and non-linear risk factors and spatial effects, the geographical difference and spatial patterns of both dietary sodium intake and 24-h urinary sodium were investigated using Bayesian geo-additive models via Markov Chain Monte Carlo simulations.

Results: A significant north-south pattern of sodium intake was found from posterior probability maps after controlling for important sociodemographic factors. Participants living in Scotland had a significantly higher dietary sodium intake and 24-h urinary sodium levels. Significantly higher sodium intake was also found in people with the lowest educational attainment (dietary sodium: coeff. 0.157 (90\% credible intervals $0.003,0.319)$, urinary sodium: $0.149(0.024,0.281))$ and in manual occupations (urinary sodium: 0.083 $(0.004,0.160))$. These coefficients indicate approximately a $5 \%, 9 \%$ and $4 \%$ difference in average sodium intake between socioeconomic groups.

Conclusions: People living in Scotland had higher salt intake than those in England and Wales. Measures of low socioeconomic position were associated with higher levels of sodium intake, after allowing for geographic location.

\section{BACKGROUND}

Raised blood pressure (BP) is the dominant, yet preventable, cause of death and disability in adults worldwide, responsible for approximately $50 \%$ of deaths from coronary heart disease (CHD) and over $60 \%$ of those from stroke. ${ }^{1}$ These are more prevalent in socially disadvantaged groups. The risk of cardiovascular disease (CVD) increases with increasing $\mathrm{BP}^{2}$ and causality is supported by randomised

\section{ARTICLE SUMMARY}

Article focus

- To evaluate the spatial effects of variation and social determinants of salt intake in Britain.

Key messages

- People living in Scotland had higher salt intake than those in England and Wales.

- Measures of low socioeconomic position were associated with higher levels of sodium intake, after allowing for geographic location.

- Special attention should be given to social and regional differences for successful salt reduction policies to avoid widening inequalities.

Strength and limitations of this study

- First study to estimate spatial variations of salt intake in Britain allowing for simultaneous linear and non-linear confounding.

- The associations are consistent, irrespective of methodological assessments of salt intake (dietary versus urinary bio-marker).

- The results are valid for the 2000-2001 period. Since then a reduction in salt intake has occurred as a result of national salt reduction campaigns. It would be important to repeat our analyses on the 2008-2011 National Diet and Nutrition Survey (NDNS) and, more importantly, to see whether the reduction in salt intake seen over the past years has led to change in the social inequality in salt consumption.

- Although the NDNS is a nationally representative survey, our results are based on white respondents only. Generalisation of the results to other ethnic groups should be made with caution.

- In the spatial analysis, the inclusion of spatially dependent random effects has a strong impact on the estimates when the number of the spatial units is large (ie, counties). With only 11 spatial units, the imposition of spatial dependence may result in over-smoothing of the estimates.

controlled clinical trials, in which lowering BP over 5 years reduces CVD by approximately the amount predicted by larger observational studies. ${ }^{3}$ The majority of CVD events attributable to BP occur in people with untreated 
pressure (about 130/80 $\mathrm{mm} \mathrm{Hg}$ ), hence a small downward shift in the distribution of BP in the whole population would achieve a large drop in CVD. ${ }^{2}$

Evidence from a wide variety of studies shows a consistent direct relation between salt intake and BP. A $4.6 \mathrm{~g}$ reduction in daily dietary intake of salt decreases BP by about $5.0 / 2.7 \mathrm{~mm} \mathrm{Hg}$ in individuals with hypertension and by $2.0 / 1.0 \mathrm{~mm} \mathrm{Hg}$ in normotensive people. ${ }^{4}$ Randomised controlled trials have consistently shown dose-response effects. ${ }^{5}$ The BP-lowering effect of reducing salt intake is effective in men and women, in all ethnic groups, in all age groups and all starting BP. Population-based interventions indicate that when salt intake is reduced, BP in the community falls. ${ }^{6-7}$ Citizens in most countries eat salt far in excess of healthy physiological requirements of about $1 \mathrm{~g} /$ day. $^{8}$ No randomised studies have described the effect of reducing the salt intake of populations on CVD-the ethical and methodological problems with such studies are similar to those with studies involving tobacco and obesity ${ }^{9}$ - but the causal link is now strong. In cohort studies, a $5 \mathrm{~g} /$ day higher salt intake is associated with a $17 \%$ greater risk of total CVD, and, crucially a $23 \%$ greater risk of stroke. ${ }^{10}$

Dietary salt, primarily sodium chloride, is commonly used for food preservation and seasoning. In the UK, up to $80 \%$ of salt consumed is hidden in processed and restaurant foods whereas only about $15 \%$ is added at the table or in cooking. A population reduction in salt intake is a very cost-effective preventive policy, ${ }^{11-23}$ with a $\$ 6$-to- $\$ 12$ savings for every $\$ 1$ spent. ${ }^{21}$ Various models of policy interventions are currently being tested or implemented worldwide through national and international initiatives. $^{824}$

CVD is more prevalent in socioeconomically deprived sections of the population. These groups are more likely to depend on cheaper unhealthy processed food diets, high in salt. The Marmot Review ${ }^{25}$ has recently reviewed the evidence that social inequalities are important determinants of ill-health in the British population, highlighting the social gradient in health inequalities, whereby people of poorer background not only die sooner but spend more of their lives with disabilities. Health inequalities arise from a complex interaction of many factors, all affected by one's economic and social status. One of these factors is bad diet and nutrition. The ensuing Marmot Report 'Fair Society, Healthy Lives' ${ }^{\text {'25 }}$ emphasises that health inequalities are preventable. It proposes ways to reduce health inequalities in England through government policies aimed at the population as a whole. Population-based strategies for prevention tend to reduce health inequalities, as they are usually 'structural'. ${ }^{26}$ Furthermore, recent evidence shows that the risk of chronic disease, like hypertension, associated with low parental social status can be modified by an improvement in social status later in life, ${ }^{27}$ suggesting targets for public health policies and political interventions. To inform these policies more information is needed at the country level.
This study aims to evaluate the determinants of salt intake in Britain by considering the effects of geographic location and other sociodemographic factors.

\section{Data and methods participants}

This analysis was conducted using the 2000-2001 British National Diet and Nutrition Survey (NDNS). The survey is a nationally representative study, covering adults aged 19-64 years living in private households in Britain. The fieldwork was undertaken between July 2000 and June 2001. Details of the fieldwork and the survey are described elsewhere. ${ }^{28} \mathrm{~A}$ total of 2251 respondents from 11 regions completed an interview $(60.8 \%$ of the total eligible sample. In this survey population, $76.6 \%$ $(\mathrm{N}=1724)$ completed a 7 -day dietary record and $64.8 \%$ $(\mathrm{N}=1459)$ provided completed 24-h urine collections. Respondents came from different ethnic groups, white representing the majority $(93.6 \%)$. Since estimation based on few respondents may not be representative for those minority ethnic groups, especially when compared by region, only white respondents were included in this analysis $(\mathrm{N}=2105)$.

Information of respondents' sociodemographic, blood pressure measurement, dietary intake and urine test were obtained. Height and weight were used to calculate body mass index (BMI) [weight/height $\left.\left(\mathrm{kg} / \mathrm{m}^{2}\right)\right]$. Systolic and diastolic blood pressures were measured three times, with the first reading discarded and the average of the rest two recorded for use. In the survey, the educational attainment was coded in seven groups: degree or equivalent; higher education below degree level; General Certificate of Education at Advanced level (GCE A) level or equivalent; General Certificate of Secondary Education (GCSE) grades A-C or equivalent; GCSE grades D-E or equivalent; other qualifications; no qualifications. Respondents' marital status was coded in seven types: married; cohabiting; single; widowed; divorced; separated; same-sex couple. Social class was recorded based on the social class of the household reference person. The standard categories were merged into three groups in the survey: non-manual (including social classes I, II and III skilled non-manual); manual (including social class III manual, IV and V); unclassified (those who were not assigned with a social class). Smoking habit was defined into three groups: non-smoker, former smoker, current smoker, using questions "Have you ever smoked a cigarette, a cigar?" and "Do you smoke cigarettes at all nowadays?" In this analysis, the educational attainment was re-categorised into four groups: degree level, A level or equivalent (below degree level, GCE A level or equivalent), GCSE or equivalent (GCSE, other qualifications or equivalent) and no qualification. The marital status was regrouped according to whether the respondent was living alone (including single, widowed, divorced and separated) or living with someone else (married, cohabiting and same-sex couple). The "unclassified" group in the social class was removed, as the number of respondents in this group was too small $(n=3)$. 
Dietary record provided sodium and energy intake and alcoholic drinking in 7 days. The averages were used as the daily consumption. However, dietary sodium did not take into account the use of table and cooking salt. The 24-h urine sample was used to measure 24-h urinary sodium excretion (mmol/day). Both sodium measurements were used in the analysis.

\section{Geographical boundaries}

The survey was carried out over 12 Government Office Regions (GOR). However, to keep consistency with previous surveys, the regions in the 2000-2001 survey have been reclassified using Standard Statistical Regions (SSRs) (see online supplementary appendix figure 1). The SSRs are composed of 11 regions: Scotland, North, Yorkshire and Humberside, North West, East Midlands, West Midlands, Wales, East Anglia, London, South East and South West. The geographical boundaries of the regions were obtained from UKBORDERS (http://edina.ac.uk/ukborders/) in order to estimate the spatial effect.

\section{Statistical methods}

In this analysis, Bayesian geo-additive mixed models were used for modelling the spatial effect taking into account the observed non-linear associations between salt intake and covariates such as age and BMI. Therefore, this modelling approach provides a unified framework for estimating spatial, linear and non-linear effects simultaneously. ${ }^{29-33}$

Four models were constructed with different combinations of covariates (see online supplementary appendix table 1). Details of model construction can be found in the appendix. The dietary sodium intake and 24-h urinary sodium excretion are all continuous variables and were not normally distributed among the selected sample but they were transformed and, therefore, a Gaussian distribution was assumed in the model construction. Cube root transformation was used for all dependent variables as it performed better than log and square root transformations, suggested by the Box-Cox transformation. The distribution of categorical factors and a reference category was also defined for effect assessment (see online supplementary appendix table 2). For dietary sodium intake (24-h urinary sodium), the following continuous covariates were included: age, BMI, alcohol drinking and energy intake (24-h urinary creatine). Deviance information criterion (DIC) was used for model selection. The model with the smallest DIC value was preferred. The analysis and model estimations were conducted in BayesX V2.0.0 (06.05.2009). ${ }^{34}$ The statistical significance level was set as $\alpha=0.05$ in the descriptive analysis and $\alpha=0.1$ in the models. The West Midlands BREC (158-01-2012) approved the analysis.

\section{RESULTS}

In total, 2105 respondents were included in the analysis. The characteristics of the respondents are shown in table 1. The average age was 42 years and $44.6 \%$ of respondents were men. The majority of the population had GCSE or equivalent qualifications (39.4\%) and A level or equivalent qualifications (24.9\%). About two-thirds $(61.6 \%)$ were married or cohabiting with others at the time of survey. The proportions of non-, former and current smokers were almost even $(29.1 \%$, $37.0 \%$ and $33.8 \%$, respectively). More people had a nonmanual job $(58.8 \%)$. Only $6.9 \%$ of respondents were on antihypertensive medications.

The median dietary sodium intake was 2611 $(\mathrm{IQR}=1243) \mathrm{mg} /$ day, which is equivalent to an estimated salt intake of $6.5 \mathrm{~g} /$ day. The median 24-h urinary sodium excretion was $140.6(99.4) \mathrm{mmol} /$ day, which is equivalent to an estimated $8.2 \mathrm{~g} /$ day. The difference between the dietary sodium intake and 24-h urinary

Table 1 Characteristics of the 2000-2001 National Diet and Nutritional Survey white respondents

\begin{tabular}{ll}
\hline Variable & Total (N=2105) \\
\hline Age (year) & $42.0(41.5,42.5)$ \\
Male (\%) & 44.6 \\
Weight (kg) & $77.1(76.3,77.8)$ \\
Height (cm) & $169.1(168.8,169.4)$ \\
Waist (cm) & $89.5(89.0,90.1)$ \\
Hip (cm) & $105.0(104.5,105.5)$ \\
Waist-hip ratio & $0.850(0.847,0.853)$ \\
BMI (kg/m ${ }^{2}$ ) & $26.9(26.6,27.1)$ \\
Systolic blood pressure (mm Hg) & $126.5(125.8,127.2)$ \\
Diastolic blood pressure (mm Hg) & $71.6(71.1,72.1)$ \\
Education (\%) & 17.2 \\
$\quad$ Higher education & 24.9 \\
A level or equivalent & 39.4 \\
GCSE or equivalent & 18.5 \\
No qualification & 38.4 \\
Marital status (\%) & 61.6 \\
$\quad$ Living alone & \\
$\quad$ Living together & 29.1 \\
Smoking habit (\%) & 37.0 \\
$\quad$ Non & 33.8 \\
Former &
\end{tabular}



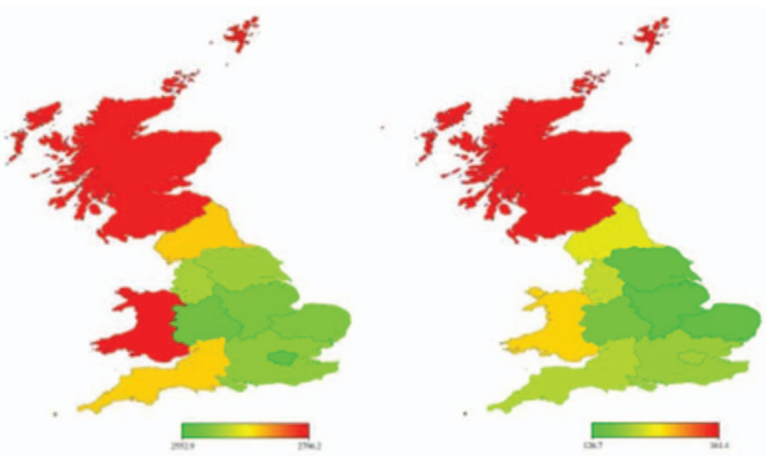

Figure 1 Observed dietary sodium intake (left panel) and 24-h urinary sodium (right panel) across Britain. The colour band represents the range of regional effect. Shades in red/ green correspond to high/low levels of dietary sodium consumption.

sodium excretion, being on average $\sim 1.7 \mathrm{~g} /$ day $(\sim 21 \%$ of total salt intake), can be deemed as an estimation of natural sources and the use of discretionary salt (ie, table and cooking salt). Allowing for inaccuracies in the estimations of salt intake with either method, these figures are in line with those of $23 \%$ reported elsewhere. $^{35}$

Figure 1 shows the observed variation of dietary sodium intake and 24-h urinary sodium excretion in Britain. Dietary sodium intake (left panel) was high in Scotland and Wales and low in the Midlands and the south-east of England. Twenty-four-hour urinary sodium (right panel) shows a gradual change from north to south, with the highest urinary sodium excretion in Scotland.

Computed DIC values of all constructed models are listed in online supplementary appendix table 3. Model 3 performed the best for both sodium measurements in terms of the DIC value. Therefore, only the results of Model 3 were presented and discussed below.

\section{Dietary sodium}

The estimated spatial effect of dietary sodium intake is shown in figure 2. The left panel indicates the estimated regional effect on dietary sodium intake. The coloured map indicates a north-south divide of dietary sodium intake. The pattern was different from the observed distribution of dietary sodium shown in figure 1 . When allowing for spatial effects, the mean sodium intake became lower in Wales. Respondents living in Scotland, however, still consumed the highest level of salt in the UK. The level of dietary sodium intake decreased with lower latitude. Respondents in southern England appeared to consume less salt. The $90 \%$ posterior probability map on the right panel of figure 2 indicates the statistical significance of the spatial variation of sodium consumption, showing that respondents in Scotland were more likely to consume a higher level of dietary sodium, while people from England and Wales did not differ significantly in their average dietary sodium intake.
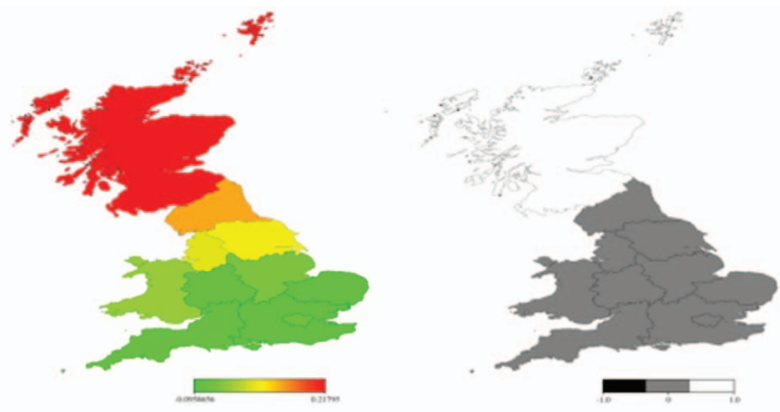

Figure 2 Estimated posterior mean residual spatial regional effects (left) and $90 \%$ posterior probability map (right) of dietary sodium intake. Left panel: the colour band represents the range of regional effect. Shades in red/green correspond to high/low levels of dietary sodium consumption. Right panel: white (value $=1.0$ ) indicates significantly positive spatial effect, grey $($ value $=0$ ) indicates a non-significant effect and black (value $=-1.0$ ), if there is any, indicates a significantly negative effect.

The estimated mean of fixed effects of categorical factors with $90 \%$ credible intervals is shown in table 2. Men and those who had lower educational attainment were more likely to consume a higher level of dietary

Table 2 Fixed effects of dietary sodium intake in the 2000-2001 National Diet and Nutrition Survey sample of white respondents

\begin{tabular}{|c|c|}
\hline Factor & $\begin{array}{l}\text { Mean ( } 90 \% \text { credible } \\
\text { intervals) }\end{array}$ \\
\hline Age & $-0.012(-0.016,-0.008)$ \\
\hline \multicolumn{2}{|l|}{ Sex } \\
\hline \multicolumn{2}{|l|}{ Female } \\
\hline Male & $0.324(0.232,0.429)$ \\
\hline BMI $\left(\mathrm{kg} / \mathrm{m}^{2}\right)$ & $0.015(0.007,0.023)$ \\
\hline \multicolumn{2}{|l|}{ Education } \\
\hline \multicolumn{2}{|l|}{$\begin{array}{l}\text { Higher Education } \\
\text { (degree level) }\end{array}$} \\
\hline A level or equivalent & $0.022(-0.103,0.146)$ \\
\hline GCSE or equivalent & $0.065(-0.057,0.199)$ \\
\hline No qualification & $0.157(0.003,0.319)$ \\
\hline \multicolumn{2}{|l|}{ Marital status } \\
\hline \multicolumn{2}{|l|}{ Living together } \\
\hline Living alone & $-0.140(-0.228,-0.055)$ \\
\hline \multicolumn{2}{|l|}{ Smoking habit } \\
\hline \multicolumn{2}{|l|}{ Non } \\
\hline Former & $-0.034(-0.136,0.071)$ \\
\hline Current & $-0.187(-0.292,-0.078)$ \\
\hline \multicolumn{2}{|l|}{ Social class } \\
\hline \multicolumn{2}{|l|}{ Non-manual work } \\
\hline Manual work & $-0.050(-0.148,0.054)$ \\
\hline $\begin{array}{l}\text { Alcohol consumption } \\
\text { (g/day) }\end{array}$ & $0.010(0.008,0.012)$ \\
\hline Energy intake (kcal/day) & $0.002(0.002,0.002)$ \\
\hline
\end{tabular}


sodium. On average, the latter had an approximately $5 \%$ higher dietary sodium intake than the group with A-level education. Furthermore, there was a gradient up to A-level education. Respondents who were smoking at the time of the survey consumed less sodium compared to non-smokers, while those living with a partner were more likely to consume more. The inclusion of use of antihypertensive medications as a covariate did not alter the results (data not shown).

\section{4-h urinary sodium}

The estimated spatial effect and posterior map of 24-h urinary sodium is shown in figure 3 . The pattern is similar to the observed distribution displayed in figure 1 and consistent with the results seen with dietary sodium. The probability map confirms the north-south pattern of salt intake with significantly higher salt intake in Scotland, even when 24-h urinary sodium is used to estimate intake.

The estimated fixed effects of 24-h urinary sodium (table 3) show that respondents with no educational attainment and from the households with lower social class were more likely to consume more salt (approximately an average of $4 \%$ and $9 \%$, respectively). Men appeared to have significantly lower salt intake, different from the result using dietary sodium intake. However, this was mainly due to the adjustment for 24-h urinary creatine in the model. By excluding urinary creatine, men again had significantly high salt intake than women, while other effects remained unchanged. The inclusion of use of antihypertensive medications as a covariate did not alter the results (data not shown).

\section{DISCUSSION}

The present analysis documents, for the first time using spatial analyses, a north-to-south gradient in salt intake across the British Isles in the period 2000-2001 with a significant and independent socioeconomic gradient.
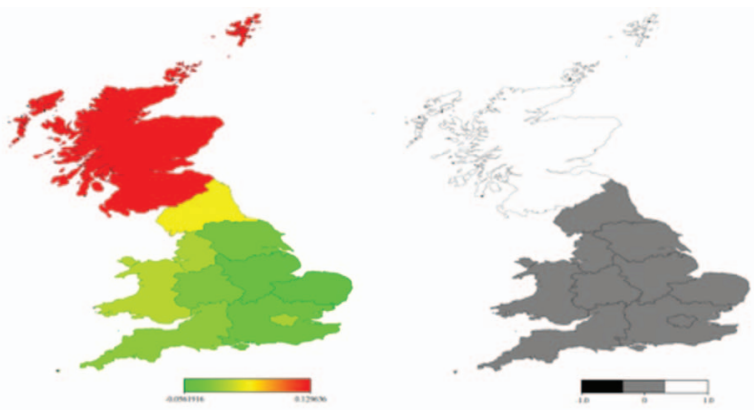

Figure 3 Estimated posterior mean residual spatial regional effects (left) and 90\% posterior probability map (right) of 24-h urinary sodium. Left panel: the colour band represents the range of regional effect. Shades in red/green correspond to high/low levels of dietary sodium consumption. Right panel: white (value $=1.0$ ) indicates significantly positive spatial effect, grey (value $=0$ ) indicates a non-significant effect and black (value $=-1.0$ ), if there is any, indicates a significantly negative effect.
Table 3 Fixed effects of 24-h urinary sodium in the 2000-2001 National Diet and Nutrition Survey sample of white respondents

\begin{tabular}{lc}
\hline Factor & $\begin{array}{l}\text { Mean }(90 \% \text { credible } \\
\text { intervals) }\end{array}$ \\
\hline Age & $-0.001(-0.004,0.002)$ \\
Sex & \\
Female & $-0.085(-0.168,-0.003)$ \\
Male & $0.014(0.007,0.020)$ \\
BMl (kg/m $\left.{ }^{2}\right)$ & \\
Education & \\
Higher education (degree & \\
level) & \\
A level or equivalent & $0.110(0.002,0.214)$ \\
GCSE or equivalent & $0.067(-0.041,0.178)$ \\
No qualification & $0.149(0.024,0.281)$ \\
Marital status & \\
Living together & \\
Living alone & $-0.023(-0.096,0.044)$ \\
Smoking habit & \\
Non & \\
Former & \\
Current & $0.043(-0.041,0.126)$ \\
Social class & $0.020(-0.069,0.110)$ \\
Non-manual work & \\
Manual work & \\
Alcohol consumption & \\
(g/day) & \\
24-h urinary creatine & \\
excretion (mmol/day) & $0.083(0.004,0.160)$ \\
\hline The estimated mean for the reference category in each factor is \\
set as 0. The credible intervals indicate statistical significance. If \\
the interval does not contain 0, the effect is considered significant. \\
GCSE, General Certificate of Secondary Education. \\
\end{tabular}

We used Bayesian geo-additive models to examine the spatial effects and to test the non-linear and linear effects of conventional sociodemographic factors. This study showed a significant spatial gradient for both dietary sodium intake and 24-h urinary sodium excretion. In particular, people living in Scotland displayed significantly higher salt intake than those living in England and Wales. Moreover, salt intake was significantly higher in those with low educational attainment and manual occupation. Educational attainment and occupation are indicators of socioeconomic status (SES), and key determinants of health. ${ }^{36-38}$ Crucially, low SES is associated with hypertension and high risks of stroke, CHD and renal failure. ${ }^{39}$ Our analysis indicates that there is an independent association between SES and salt intake.

\section{Strengths and limitations}

This is the first study to estimate spatial variations of salt intake and to establish the contribution of known and unknown confounders to such geographical distribution, using both linear and non-linear effects, all estimated simultaneously. The associations described are consistent, irrespective of methodological assessments of salt intake 
(dietary versus urinary bio-marker). The present analysis refers to 2000-2001. While the results are valid for that period, since then a reduction in salt intake has occurred as a result of national salt reduction campaigns. The British government set a target of $6 \mathrm{~g} /$ person/day and in 2004, through the Food Standards Agency, started a programme of population salt reduction through media campaigns to increase public awareness and demand for change, engagement with the food industry on a voluntary basis to set targets for sodium content in foods, and to obtain reformulation of many common food categories, and repeated national surveys using 24-h urine collections to monitor intake. ${ }^{40}$ Ministers also proposed regulation if the industry refused to make reductions voluntarily. As a result, the mean salt intake in the UK fell from $9.5 \mathrm{~g} /$ day in 2001 to $8.6 \mathrm{~g} /$ day in $2008,{ }^{41}$ and further to $8.1 \mathrm{~g} /$ day in 2011 in England. ${ }^{42}$ The overall reduction in salt intake may have occurred across geographical areas and socioeconomic groups or, as it is often the case when behavioural approaches are preferred to more radical top-down policies, it may have further widened the social gradient. It would be important to repeat our analyses on the 2008-2011 NDNS crucially to document whether the reduction in salt intake seen over the past few years has modified the social inequality in salt consumption observed previously. The definition of socioeconomic position was limited to education and occupation, as the only measures available in the NDNS database. It would have been extremely informative if more sensitive measures of deprivation had been available. Although the NDNS is a nationally representative survey, our results are based on white respondents only. Other ethnic groups were not included in this analysis due to the small representation. Generalisation of the results to the whole population should therefore be made with caution. Since ethnic minorities cluster around big conurbations (eg, London, Birmingham, the Midlands, Manchester, Liverpool), representing a significant proportion of the total population, it is possible that we may have underestimated the association of salt intake with socioeconomic gradient in some areas with larger ethnic representations. Larger sample size should be obtained from the minority ethnic groups for representative and robust estimations to be used at regional levels.

In the spatial analysis, the inclusion of spatially dependent random effects has a strong impact on the estimates when the number of the spatial units is large (ie, counties). With only 11 spatial units, the imposition of spatial dependence may result in over-smoothing of the estimates. Regional classification is another limitation. Higher classification averages out more subtle spatial variation. Lower geographical information, such as district and county, may produce more accurate estimations and provide better indications to policy-makers and other stakeholders to identify areas where political support and health intervention are needed. However, the information was not available in the 2000-2001 NDNS.

\section{Context}

Unsurprisingly, the prevention of CVD is a top priority for action worldwide. Among the five priority interventions, reduction of populations' salt intake is listed as second after global tobacco control. It is estimated that a $15 \%$ reduction in salt intake would avert 8.5 million deaths over 10 years worldwide. ${ }^{43}$ The global goal set by WHO is to reduce salt intake to less than $5 \mathrm{~g} /$ person/ day by $2025,{ }^{44}$ with some countries aiming for even lower levels in the longer term. ${ }^{45}$ Progress towards this target could begin through mass media campaigns and reformulation of existing and new food products by industry. ${ }^{8}$ Since in most developed economies the majority of dietary salt is added during commercial food production, government regulation may also be needed. ${ }^{824}$ Many countries have committed themselves to salt reduction initiatives, often led by government, sometimes led by non-governmental organisations, rarely led by industry. ${ }^{46}$ The expected reductions in vascular events would be comparable with those currently projected for interventions targeting tobacco, obesity or primary prevention with statins and anti-hypertensives. However, it is not clear as to how the reduction in salt intake, and the expected health gains would be distributed across socioeconomic groups.

\section{Implications for policy}

Evaluation of the spatial variation of salt intake can be useful to public health monitoring of intake levels. The identification of populations with high salt intake and their regional variations may provide additional useful information not only to increase public awareness but also to policy-makers, food industry and other stakeholders to undertake more effective and pertinent actions to prevent CVD. Even with the limitations acknowledged above, this study demonstrates the usefulness of considering spatial variation in the analysis of salt intake, suggesting that Bayesian geo-additive models can be used as an innovative monitoring and evaluation tool. Our study shows significant spatial and socioeconomic inequalities of salt intake. People with high salt intake have higher risk of hypertension and CVD compared to those with low salt consumption. The significant reduction in average population salt intake in Britain in the period 2004-2011 is an achievement to celebrate. However, it may conceal inequalities in that it would underestimate the health risks in people of low SES, those who need prevention most. The diet of disadvantaged socioeconomic groups is made of low-quality, salt-dense, high-fat, high-calorie unhealthy cheap foods. Behavioural approach to healthy eating, while needed to increase awareness, will not bring about the changes necessary to halt and revert the cardiovascular epidemic and would widen inequalities. ${ }^{82627}$ An effective way to reduce salt intake across all socioeconomic groups is to gradually reduce the salt content in food, such as bread, a major source of salt, because most of the salt intake is hidden in processed food. If the government can strengthen the 
monitoring of salt reduction and reformulation in those foods, better health outcomes should be expected.

\section{CONCLUSIONS}

In conclusion, our analysis describes a north-south pattern of salt intake across Britain with people living in Scotland having higher salt intake than those in England and Wales. After allowing for geographic location, measures of low socioeconomic status are associated with higher salt intake, indicating a higher risk of hypertension and CVD. We should pay attention to the impact of salt reduction policies on social and regional differences in salt intake for equitable implementation. By doing so, we would contribute to two of the six policy objectives set in the 2010 Marmot Report: ensuring a healthy standard of living for all and strengthening the role and impact of ill-health prevention. ${ }^{25}$

Contributors FPC developed the idea, obtained funding, supervised the analysis and drafted the manuscript. CJ carried out the statistical analysis and prepared the draft methods and results. NBK developed the original statistical methods and took part in discussions. All made significant contributions to the draft manuscript. FPC acts as guarantor.

Funding The BUPA Foundation (MR-12-002).

Competing interests FPC is unpaid member of CASH, WASH, unpaid technical advisor to the WHO and the PAHO, Individual member of the National Heart Forum, past member of the Executive Committee and Trustee of the British Hypertension Society, past member of the NICE CVD population prevention guideline development group.

Ethics approval West Midlands BREC (158-01-2012).

Provenance and peer review Not commissioned; externally peer reviewed.

Data sharing statement No additional data are available.

Disclosure The publication does not necessarily represent the decisions or the stated policy of WHO and the designations employed and the presentation of material do not imply the expression of any opinion on the part of WHO.

\section{REFERENCES}

1. Lopez AD, Mathers CD, Ezzati M, et al. Global and regional burden of disease and risk factors, 2001: systematic analysis of population health data. Lancet 2006;367:1747-57.

2. Lewington S, Clarke R, Qizilbash N, et al. Age-specific relevance of usual blood pressure to vascular mortality: a meta-analysis of individual data for one million adults in 61 prospective studies. Lancet 2002;360:1903-13.

3. Blood Pressure Lowering Treatment Trialists' Collaboration. Effects of different blood pressure lowering regimens on major cardiovascular events: results of prospectively designed overviews of randomised trials. Lancet 2003;362:1527-35.

4. He FJ, MacGregor GA. Effect of modest salt reduction on blood pressure: a meta-analysis of randomized trials. Implications for public health. J Hum Hypertens 2002;16:761-70.

5. He FJ, MacGregor GA. How far should salt intake be reduced? Hypertension 2003;42:1093-9.

6. Forte JG, Miguel JM, Miguel MJ, et al. Salt and blood pressure: a community trial. J Hum Hypertens 1989;3:179-84.

7. Takahashi Y, Sasaki S, Okubo S, et al. Blood pressure change in a free-living population based dietary modification study in Japan. $J$ Hypertens 2006;24:451-8.

8. Cappuccio FP, Capewell S, Lincoln P, et al. Policy options to reduce population salt intake. Br Med J 2011;343:402-5.

9. Strazzullo P. Benefit assessment of dietary salt reduction: while the doctors study, should more people die? J Hypertens 2011;29:829-31.
10. Strazzullo P, D'Elia L, Kandala NB, et al. Salt intake, stroke and cardiovascular disease: a meta-analysis of prospective studies. BMJ 2009;339:b4567.

11. Selmer RM, Kristiansen IS, Haglerod A, et al. Cost and health consequences of reducing the population intake of salt. $J$ Epidemiol Community Health 2000;54:697-702.

12. Murray CJ, Lauer JA, Hutubessy RC, et al. Effectiveness and costs of interventions to lower systolic blood pressure and cholesterol: a global and regional analysis on reduction of cardiovascular-disease risk. Lancet 2003;361:717-25.

13. Chang HY, Hu YW, Yue CSJ, et al. Effect of potassium-enriched salt on cardiovascular mortality and medical expenses of elderly men. Am J Clin Nutr 2006;83:1289-96.

14. Joffres MR, Campbell NR, Manns B, et al. Estimate of the benefits of a population-based reduction in dietary sodium additives on hypertension and its related health care costs in Canada. Can J Cardiol 2007:23:437-43.

15. Asaria $P$, Chisholm D, Mathers $C$, et al. Chronic disease prevention: health effects and financial costs of strategies to reduce salt intake and control tobacco use. Lancet 2007;370:2044-53.

16. Palar K, Sturm R. Potential societal savings from reduced sodium consumption in the U.S. adult population. Am J Health Promot 2009:24:49-57.

17. Dall TM, Fulgoni VL III, Zhang Y, et al. Potential health benefits and medical cost savings from calorie, sodium, and saturated fat reductions in the American diet. Am J Health Promot 2009;23:412-22.

18. Dall TM, Fulgoni VL 3rd, Zhang Y, et al. Predicted national productivity implications of calorie and sodium reductions in the American diet. Am J Health Promot 2009;23:423-30.

19. Rubinstein A, Garcia Marti S, Souto A, et al. Generalized cost-effectiveness analysis of a package of interventions to reduce cardiovascular disease in Buenos Aires. Argentina. Cost Effect Res Allocation 2009;7:10.

20. Smith-Spangler CM, Juusola JL, Enns EA, et al. Population strategies to decrease sodium intake and the burden of cardiovascular disease. A cost-effectiveness analysis. Ann Intern Med 2010;152:481-7.

21. Bibbins-Domingo K, Chertow GM, Coxson PG, et al. Projected effect of dietary salt reductions on future cardiovascular disease. $N$ Engl J Med 2010;362:590-9.

22. Cobiac LJ, Vos T, Veerman JL. Cost-effectiveness of interventions to reduce dietary salt intake. Heart 2010;96:1920-5.

23. Burton $P$, Andronis L, Briggs $A$, et al. Effectiveness and cost effectiveness of cardiovascular disease prevention in whole populations: modelling study. Br Med J 2011;343:d4044.

24. Cappuccio FP. Salt and cardiovascular disease. Br Med J 2007;334:859-60.

25. Fair Society, Healthy Lives. The Marmot Review. Strategic Review of Health Inequalities in England post-2010. Published by The Marmot Review 2010;1-238.

26. Capewell S, Graham H. Will cardiovascular disease prevention widen health inequalities? PLoS Med 2010;7:e1000320.

27. Hosberg L, Cnattingius S, Lundholm C, et al. Intergenerational socia mobility and the risk of hypertension. J Epidemiol Commun Health 2012;66:6 e9.

28. Hoare J, Henderson L, Bates CJ, et al. The National Diet and Nutrition Survey: Adults Aged 19-64 Years, volume 5: Summary Report. London: HMSO; 2004.

29. Kandala N-G, Ji C, Stallard N, et al. Spatial analysis of risk factors for childhood morbidity in Nigeria. Am J Trop Med Hyg 2007;77:770-8.

30. Kandala N-B, Ji C, Cappuccio FP, et al. The epidemiology of HIV infection in Zambia. AIDS Care 2008;20:812-19.

31. Kandala N-B, Ji C, Stallard N, et al. Morbidity from diarrhoea, cough and fever among young children in Nigeria. Ann Trop Med Parasitol 2008;102:427-45.

32. Kandala N-B, Emina JBO, Kikhela PDZ, et al. Diarrhoea acute respiratory infection, and fever among children in the Democratic Republic of Congo (DRC). Soc Sci Med 2009;68:1728-36.

33. Kandala N-B, Madungu $P$, Emina J, et al. Malnutrition among children under the age of five in the Democratic Republic of Congo: does geographic location matter? BMC Public Health 2011:11:261.

34. Brezger A, Kneib T, Lang S, et al. Software for Bayesian inference based on Markov chain Monte Carlo simulation techniques. J Statist Software 2005;14:11.

35. Mattes RD, Donnelly D. Relative contributions of dietary sodium sources. J Am Coll Nutr 1991;10:383-93.

36. Illsley R, Baker D. Contextual variations in the meaning of health inequality. Soc Sci Med 1991;32:359-65.

37. Mackenbach JP, Stirbu I, Roskam AJ, et al. Socioeconomic inequalities in health in 22 European countries. $N$ Engl J Med 2008;358:2468-81 
38. Adler NE, Boyce T, Chesney MA, et al. Socioeconomic status and health. The challenge of the gradient. Am Psychol 1994;49:15-24.

39. Colhoun HM, Hemingway H, Poulter NR. Socio-economic status and blood pressure: an overview analysis. J Hum Hypertens 1998;12:91-110.

40. He FJ, MacGregor GA. Reducing population salt intake worldwide: from evidence to implementation. Prog Cardiovasc Dis 2010;52:363-82.

41. Cappuccio FP, Capewell S. How to cut down salt intake in populations. Heart 2010;96:1863-4.

42. Sadler K, Nicholson S, Steer T, et al. National Diet and Nutrition Survey. Assessment of Dietary Sodium in Adults
(Aged 19-64) in London, England, 2011. Department of Health of England, 2012.

43. Cappuccio FP, Capewell S. A sprinkling of doubt. New Sci 2010 May $1 ; 22-3$.

44. Beaglehole R, Bonita R, Horton R, et al. Priority actions for the non-communicable disease crisis. Lancet 2011;377:1438-47.

45. National Institute for Health and Clinical Excellence. Prevention of cardiovascular disease at population level. NICE Public Health Guidance 25. London, 2010;1-124.

46. Webster JL, Dunford EK, Hawkes C, et al. Salt reduction initiatives around the world. J Hypertens 2011;29:1043-50. 